\title{
Nghiên cứu tổng quan về dạy học theo quan điểm sư phạm tương tác
}

\section{Overview of teaching from the perspective of pedagogical interaction}

\author{
Trần Mậu Chung ${ }^{*}$ \\ ${ }^{1}$ Học viện Chính trị, Bộ Quốc phòng, Việt Nam \\ "Tác giả liên hệ, Email: Chunglq76@gmail.com
}

THÔNG TIN

DOI: $10.46223 / \mathrm{HCMCOUJS}$. soci.vi.16.2.1996.2021

Ngày nhận: 14/07/2021

Ngày nhận lại: 26/08/2021

Duyệt đăng: 26/08/2021

Tì khóa:

người dạy; người học; môi trường dạy học; quan điểm sư phạm tương tác

Keywords:

teachers; students; teaching environment; the perspective of pedagogical interaction; interactive pedagogical point of view

\section{TÓM TẮT}

Dạy học theo quan điểm sư phạm tương tác là một hướng tiếp cận dạy học hiện đại, đã và đang thu hút được nhiều nhà khoa học, nhà giáo dục trong và ngoài nước nghiên cứu. Để làm cơ sở, tiền đề cho nghiên cứu vấn đề vận dụng quan điểm sư phạm tương tác trong dạy các môn khoa học xã hội và nhân văn đạt hiệu quả thiết thực. Chúng tôi đã tiến hành nghiên cứu tổng quan về dạy học theo quan điểm sư phạm tương tác qua các nghiên cứu của các tác giả trong và ngoài nước trên các hướng như sau: Nghiên cứu về vai trò và mối quan hệ tương tác các thành tố của quá trình dạy học; nghiên cứu về cơ sở lý thuyết, phương pháp và kỹ thuật dạy học theo quan điểm sư phạm tương tác; Nghiên cứu về ứng dụng công nghệ thông tin và truyền thông trong dạy học theo quan điểm sư phạm tương tác và nghiên cứu về vận dụng quan điểm sư phạm tương tác trong các môn học ở các nhà trường.

ABSTRACT
Teaching from the perspective of pedagogical interaction is a
modern teaching approach, which has attracted many domestic
and foreign educational research projects. To serve as a basis for
the research of applying interactive pedagogical in teaching social
sciences and humanities with practical efficiency, we have
conducted general research on teaching from the perspective of
interactive pedagogy through the studies of domestic and foreign
authors on the following directions: Research on the role and
interaction relationship of components of the teaching process; on
theoretical foundations, teaching methods and techniques based
on interactive pedagogy; on applying information and
communication technology in teaching from the perspective of
pedagogical interaction and on using interactive pedagogical
point of view in education in schools.

\section{1. Đặt vấn đề}

Cuộc cách mạng công nghiệp lần thứ tư, xu hướng toàn cầu hóa và hội nhập quốc tế đang 
đặt giáo dục Việt Nam cả thời cơ và những thách thức mới, cần tiếp tục đổi mới để hòa nhập và phát triển, nâng cao chất lượng nguồn nhân phục vụ cho sự nghiệp công nghiệp hóa, hiện đại hóa đất nước. Nghị quyết của Đảng về đổi mới căn bản toàn diện giáo dục và đào tạo đã chỉ rõ: "Chuyển mạnh quá trình giáo dục từ chủ yếu trang bị kiến thức sang phát triển toàn diện năng lực và phẩm chất người học" (Đảng Cộng Sản Việt Nam, 2013, p. 2). Tuy nhiên, đổi mới giáo dục theo cách tiếp cận nào để nó mang lại hiệu quả thiết thực? Đây là vấn đề thu hút nhiều công trình nghiên cứu. Dạy học theo quan điểm sư phạm tương tác là một hướng tiếp cận dạy học hiện đại, nhờ sự tương tác giữa người dạy, người học và môi trường làm cho quá trình dạy học được vận hành, phát triển. Để làm cơ sở cho các nghiên cứu ứng dụng quan điểm này trong dạy và học. Chúng tôi đi sâu nghiên cứu tổng quan về dạy học theo quan điểm sư phạm tương tác.

\section{Phương pháp nghiên cứu}

Nội dung bài viết đi sâu về lý luận, nên tác giả sử dụng các phương pháp nghiên cứu lý thuyết như phân tích và tổng hợp tài liệu; khái quát hóa và trừu tượng hóa; so sánh và hệ thống hóa lý thuyết, dựa trên các tài liệu trong nước và trên thế giới có liên quan đến vấn đề nghiên cứu: dạy học theo Quan Điểm Sư Phạm Tương tác (QĐSPTT) và vận dụng QĐSPTT trong dạy học các môn học cụ thể, ở các cấp học từ phổ thông đến đại học. Phân tích và hệ thống hoá lại để làm cơ sở lý luận của đề tài nghiên cứu.

\section{Nội dung nghiên cứu}

\subsection{Nghiên cứu về dạy học theo quan điểm sư phạm tương tác ở nước ngoài}

Dạy học được thực hiện bởi sự tác động qua lại, phối hợp của các thành tố trong cấu trúc của Quá Trình Dạy Học (QTDH). Sự tác động qua lại giữa các thành tố này tạo nên sự vận động, phát triển của cả QTDH theo mục tiêu xác định.

\section{Nghiên cứu về vai trò và mối quan hệ tuơng tác các thành tố của quá trình dạy học}

Thời kỳ cổ đại, nhiều nhà giáo dục chỉ thấy được vai trò của người dạy, người học cũng như mối quan hệ giữa hoạt động dạy và hoạt động học. Tiêu biểu có Khổng Tử (551 - 479 tr.CN) với tư tưởng nổi bật “Giáo học tưong trương” (Ha \& Dao, 1998) (Người dạy và người học tương tác thúc đẩy nhau cùng phát triển) đến nay tử tưởng của ông vẫn còn ảnh hưởng lớn đến hoạt động dạy học và giáo dục trong nhà trường.

Socrate (469 - 399 tr.CN) nhà triết học cổ đại Hy Lạp. Đóng góp quan trọng nhất của ông cho nhân loại là phương pháp "truy vấn biện chứng," hay còn gọi "phương pháp Socrates." Đây là quá trình hỏi - đáp giữa người dạy và người học; trong đó, người dạy là người "nâng đỗ," "người đỡ đẻ" những sáng kiến của người học để giúp họ tìm ra chân lý (Ha \& Dao, 1998).

Trải qua các thời kỳ lịch sử khác nhau, tư tưởng về dạy học tương tác tiếp tục được khẳng định và phát triển với sự đóng góp của các nhà giáo dục: J. A. Comenxki (1592 - 1670), John Locke (1632 - 1704); J. J. Rousseau (1712 - 1778), J. H. Pestalozzi (1746 - 1827); A. Diesterweg (1790 - 1866), ... Đặc biệt, cuộc cải cách giáo dục những năm cuối thế kỷ XIX đầu thế kỷ XX đã mở ra nhiều hướng đổi mới dạy học tập trung vào hoạt động của người học. Các nhà giáo dục Nga như: N. V. Savin, T. A. Ilina, B. P. Êsipốp, Iu. K. Babanxki, ... cũng đã quan tâm đến mối quan hệ qua lại giữa các thành tố của QTDH, đặc biệt là mối quan hệ của người dạy và nguời hoc, mối quan hệ trong tam giác su phạm: nguời dạy - nguời học-nọi dung. Tuy nhiên, ở hướng nghiên cứu này, các tác giả chủ yếu tập trung vào mối quan hệ tương tác giữa người dạy và người học, chưa bao quát được hết cấu trúc, chức năng của từng thành tố, nhất là thành tố môi trường chưa thật sự được quan tâm nghiên cứu, đặc biệt là ảnh hưởng của môi trường tới người dạy, người học trong dạy học.

Hương nghiên cúu về cơ sở lý thuyết, phương pháp và kỹ thuật dạy học theo quan điểm 
sur phạm tương tác

J. Dewey (1859 - 1952) cho rằng con người sống cần tương tác, làm việc cùng nhau để giải quyết vấn đề và cần được trải nghiệm những vấn đề đó ngay từ trong nhà trường. Ông đề cao vai trò người học "lấy nguời học làm trung tâm," và đề xuất xây dựng "nhà truờng hoạt động", "dạy học qua việc làm." Tư tưởng giáo dục của Deway có một luận điểm quan trọng là tiền đề cho QĐSPTT đó là sự ảnh hưởng của các "tuoong tác xã hội" trong dạy học (T. Q. Pham, 2013).

X. Vưgốtxki (1896 - 1934), chỉ ra sự phát triển nhận thức bắt nguồn từ các "tuoong tác xã hội" việc học tập tốt nhất khi tác động được tới "vùng phát triển gần nhất." Ông cho rằng quá trình nhận thức của người học thường xuyên diễn ra ở hai trình độ đó là trình độ hiện tại và vùng phát triển gần nhất. Ở trình độ hiện tại người học có thể độc lập giải quyết được các vấn đề, nhiệm vụ bằng chính năng lực của bản thân mình mà không cần bất cứ sự trợ giúp, giúp đỡ nào từ phía người dạy. Còn khi người học ở trạng thái vùng phát triển gần nhất để giải quyết được vấn đề, hoàn thành nhiệm vụ người dạy đặt ra, người học phải tham gia thảo luận, phản biện, tranh luận, ... có nghĩa là người học thực hiện tương tác đa đạng với thầy, với bạn học, với môi trường. Nếu không có hoạt động tương tác, người học không thể tự mình giải quyết được nhiệm vụ học tập. Cơ chế của việc học là cơ chế kết hợp giữa học cá nhân và học hợp tác, dạy học chính là sự hợp tác hai chiều, thầy hướng dẫn, đạo diễn và trò tự giác, tích cực, độc lập, sáng tạo. Với quan điểm dạy học tương tác phát triển của ông đã mở ra một trào lưu dạy học mới, Phương Pháp Dạy Học (PPDH) tích cực (Vu, 2008).

Đến những năm 70 của thế kỷ XX, nhóm các tác giả thuộc viện Đại học đào tạo giáo viên (IUFM) ở Gremonoble (Pháp) là Guy Brousseau, Claude Comiti, M. Artigue, R. Douady, C. Margolinas, ... đã quan niệm cấu trúc QTDH gồm 04 nhân tố: Người học - Người dạy - Kiến thức - Môi trường (điều kiện dạy học cụ thể). Theo nhóm tác giả, môi trường không phải là một yếu tố tĩnh, bất động, mà là một thành tố thuộc cấu trúc hoạt động dạy học; môi trường không chỉ ảnh hưởng đến người học, mà quan trọng ở chỗ sự thích nghi của người học trước những đòi hỏi của môi trường đã thay đổi người học, người dạy và hoạt động của họ và làm thay đổi cả chính môi trường (T. V. Phan, 2010).

Trong cuốn sách "Education for twenty-firstcentury: Asia-Pacific perspective" (Nền giáo dục thế kỷ XXI, nhũng triển vọng của châu Á-Thái Bình Dưong) (Singh, 1991) đã đưa ra các yêu cầu QTDH phải là quá trình sáng tạo, "chuyển tù quá trình học tập truyền thu sang quá trình tuoong tác, hợp tác, định huớng, huớng dẫn cho nguời học để kích thích phát triển tối đa mọi tiềm năng sáng tạo của người hoc, người học là người tích cực tham gia vào quá trình hoc tập, dạy học" (Singh, 1991) "QTDH là quá trình tưong tác liên tục, tù̀ nhiều phía: tù bạn bè, tù cộng đồng, noi làm việc và quá trình tham gia tích cưc vào các hoạt động xã hội."

Cuốn sách "Một số vấn đề về phuoong pháp giáo dục" (Jean, 1993) đã cho rằng "tế bào của QTDH là sự tác động qua lại giữa ngườ học và người dạy với đối tượng mà người dạy cần nắm vũung để dạy còn người học cần nắm vũng để học." Do đó xuất hiện một tam giác thể hiện mối quan hệ giữa giáo viên - học sinh - đối tượng. Tam giác có ba đỉnh là giáo viên, học sinh và đối tượng thể hiện ba mối quan hệ cụ thể: (1) Quan hệ giáo viên và đối tượng (giáo viên nắm vững tri thức và cách dạy); (2) Quan hệ học sinh và đối tượng (học sinh nắm được cách học, cách chiếm lĩnh tri thức); (3) Quan hệ giáo viên và học sinh (quan hệ sư phạm và cá nhân). Đối tượng có thể là mục tiêu, nội dung và phương pháp, phương tiện dạy học. Jean nêu ra cấu trúc dạy học gồm ba yếu tố người dạy - người học - đối tượng. Đối tượng theo quan niệm của ông được nhìn nhận trên bình diện rộng, nó bao gồm cả môi trường dạy học.

Cuốn sách đã được dịch sang tiếng Việt có tên "Tiến tới một phuoong pháp su phạm 
tuơng tác" (Denomme \& Roy, 2000). Cấu trúc hoạt động dạy học được quy gộp trong một "bộ $b a$ " gồm người học - người dạy - môi trường. Nội dung cốt lõi, xuyên suốt cuốn sách nhấn mạnh việc dạy học phải tập trung vào người học, người học là người kiến tạo kiến thức cho bản thân bằng sự huy động tiềm năng của chính mình (bộ máy học, vốn kinh nghiệm, trí tuệ, ...); sự tương tác giữa người dạy- người học- môi trường làm cho QTDH được vận hành, phát triển bền vững nhờ động lực được tạo ra bởi tương tác hoạt động dạy và học với môi trường; yếu tố "kiến thức" được các tác giả xem như một yếu tố khách quan mà người dạy muốn hướng người học chiếm lĩnh và yếu tố môi trường được quan tâm nghiên cứu trong mối quan hệ tương tác với người dạy, người học. Với cách tiếp cận này sẽ giúp cho người dạy có cách nhìn toàn diện, đầy đủ, năng động mang lại thành công nhiều nhất cho người học và dạy học đem lại hiệu quả.

Trong cuốn sách khác "Su phạm tương tác một tiếp cận khoa hoc thần kinh về họ và dạy" (Roy \& Denomme, 2009) nhóm tác giả Jean - Marc Denommé et Madeleine Roy để tiếp tục phát triển những luận điểm khoa học về sư phạm tương tác. Nhóm tác giả đã đi sâu mô tả phân tích làm rõ hơn các luận điểm: Người học học như thế nào? Người dạy dạy như thế nào? Môi trường học và môi trường dạy ảnh hưởng đến hoạt động sư phạm như thế nào? Đặc biệt, nhóm tác giả đã phân tích rõ cơ chế học tập của người học dựa trên thành tựu nghiên cứu của khoa học sinh lý học thần kinh về "bộ máy học," cơ chế hoạt động của hệ thần kinh trung ương, hệ thần kinh ngoại biên, các năng lực bổ trợ hệ thần kinh, các hành vi căn bản của người học. Nhóm tác giả xác nhận các thành phần không thể thiếu của sư phạm học tương tác, đó là sư phạm hứng thú, sư phạm hợp tác, sư phạm thành công, các khâu của hoạt động dạy học (như lập kế hoạch, tổ chức hoạt động và hợp tác). Yếu tố môi trường được nhóm tác giả mô tả một cách toàn diện và phong phú (môi trường vật chất, môi trường tinh thần, môi trường bên ngoài và môi trường bên trong) mà trước đây, trong lý luận dạy học các điều kiện này chưa được quan tâm và đánh giá đúng mức ảnh hưởng của chúng đến việc tổ chức hoạt động sư phạm của người giáo viên.

Trong cuốn sách "Encyclopedia of interactive learning" (Pometun, 2009). Tác giả cuốn sách đã trình bày các khái niệm: tương tác, học tập tương tác, bản chất của mô hình học tập tương tác, điều kiện để triển khai hiệu quả mô hình dạy học tương tác, phân loại và hệ thống hóa các phương pháp và kỹ thuật học tập tương tác được sử dụng trong QTDH, cũng như những kỹ thuật và chiến lược để tạo môi trường học tập tích cực.

Bài báo khoa học "Senior High School Student Biology Learning in Interactive Teaching" (Lu, Cowie, \& Jones, 2010) đưa ra 05 nguyên tắc là nền tảng của dạy học tương tác, đó là: (1) Thay đổi vai trò của giáo viên và học sinh; (2) Khuyến khích sự tương tác giữa học sinh và giáo viên, giữa học sinh và học sinh; (3) Nhấn mạnh cả kết quả lĩnh hội tri thức và quá trình học tập; (4) Liên hệ nội dung giảng dạy với cuộc sống hàng ngày; (5) Đổi mới đánh giá trong học tập. Đồng thời, QTDH tập trung vào sự tương tác, tạo nhiều cơ hội cho giáo viên tìm hiểu, khai thác sự quan tâm của học sinh về kết quả học tập dự kiến và động lực học tập của họ.

Nghiên cứu về úng dụng công nghệ thông tin và truyền thông trong dạy hoc theo quan điểm sư phạm tương tác

Tác giả Sessoms "Interactive Instruction: Creating Interactive Learning Environments Through Tomorrow's Teachers" (Sessoms, 2008) cho rằng có nhiều quan niệm khác nhau về dạy học tương tác, ví dụ khi bạn sử dụng các trang web Internet nhất định, tương tác có nghĩa là nhấp chuột vào một liên kết và truy cập vào văn bản. Học tương tác khác với học theo kiểu truyền thống, nếu như học theo kiểu truyền thống sinh viên ngồi chăm chú nghe ghi chép đầy đủ để tiếp thu kiến thức từ giáo viên truyền thụ. "Học tập tương tác có nghĩa là sinh viên tham gia tích cưc vào quá trình học tập. Với một môi truờng học tập được tổ chức phù hợp đặc điểm nhận thức của sinh viên" (Sessoms, 2008). Dạy học tương tác là sự kết hợp của việc dạy và học tương tác 
được hỗ trợ bởi các thiết bị công nghệ. Trong triển khai dạy học được kết hợp vận dụng lý thuyết kiến tạo kết hợp với việc sử dụng màn chiếu tương tác và công cụ Web 2.0. Việc kết hợp các công cụ tạo ra một môi trường tương tác, cho phép người dạy có cơ hội để dạy trong một môi trường dạy học tương tác. Nghiên cứu của tác giả đã góp phần phát triển dạy học tương tác trực tuyến với sự hỗ trợ của thiết bị thông tin và truyền thông.

\subsection{Nghiên cứu về dạy học theo quan điểm sư phạm tương tác ở trong nước}

Ở Việt Nam, từ nhiều năm qua đã có nhiều công trình nghiên cứu, với các cách tiếp cận khác nhau về dạy học theo QĐSPTT và vận dụng quan điểm này trong dạy học ở các môn học, bậc học khác nhau.

Hướng nghiên cứu về vai trò và mối quan hệ tương tác các thành tố của quá trình dạy $h o c$

Tác giả B. K. Le (1993) Tổ chức quá trình dạy học đại học và D. N. Do (1997) Tiếp cận hiện đại hoạt động dạy học trong cuốn sách các tác giả chỉ ra rằng cấu trúc QTDH gồm ba nhân tố: khái niệm khoa học, người dạy, người học, ba nhân tố có mối quan hệ tác động qua lại với nhau. Trong đó hệ thống khái niệm khoa học là nội dung dạy học, người dạy với hoạt động dạy, người học với hoạt động học có mối quan hệ biện chứng, tương tác với nhau. Môi trường là hệ thống đối mặt với người học, ngoài thông tin khoa học (các môn học) còn có rất nhiều thông tin khác trong môi trường dạy học như phim ảnh, ca nhạc, ... đều chi phối hoạt động học tập của người học.

Trong cuốn sách, Phwơng pháp dạy và học đại học (T. C. Nguyen \& Le, 2004). Các tác giả chỉ ra rằng: "Tương tác không phải là một quá trình đơn giản mà là một hiện tuợng đa diện. Do đó, có thể có rất nhiều hình thức hợp tác nhu học nhóm, nghiên cúu theo nhóm, thảo luận ở tổ, lớp, ở khối lớp, ... tương tác giũa người dạy và ngườ học, tuoong tác trong nhóm cùng độ tuổi, trình độ."

Luận giải các tính chất của QTDH trong cuốn sách, Lý luận dạy học đại học (H. V. Dang \& Ha, 2009); Giáo dục học hiện đại (Thai, 2001) trong cuốn sách các tác giả đã luận giải các tính chất của QTDH bao gồm: QTDH là một quá trình nhận thức; QTDH là một quá trình tâm lý và mặt xã hội của QTDH. Tác giả khẳng định "dạy học là sư tương tác giũa người và người, người và xã họi (tập thể lớp, nhóm bạn, gia đình...)" quan điểm dạy học tương tác của tác giả được xem xét, nhìn nhận dựa trên quan điểm xã hội học.

Hướng nghiên cưu về co sở lý thuyết, phuoong pháp và kỹ thuật dạy học theo quan điểm sư phạm tương tác

Tác giả N. T. Phan (2005) trong cuốn sách Dạy học và phương pháp dạy học trong nhà trường đã nêu ra các luận điểm quan trọng, có giá trị định hướng các phương pháp tổ chức hành động học "các phương pháp tổ chưc hành động tưong tác có cơ sở tâm lý học, xã họi học sâu sắc và vĩng chắc mà trục tiếp là lý thuyết tương tác phát triển, lý thuyết tương tác biểu trung, lý thuyết vai trò, lý thuyết kịch" (N. T. Phan, 2005). Luận điểm bao trùm các cá nhân trong xã hội không tồn tại như một ốc đảo, mà luôn luôn có quan hệ hữu cơ và tương tác với người khác. Nói đúng hơn con người chỉ tồn tại và phát triển thông qua sự tương tác với người khác. Trong quá trình tương tác, cá nhân học được các ứng xử từ hành vi của người khác và nhận ra hành vi của mình thông qua phản ứng của người đối diện, từ đó điều chỉnh hành vi của mình. Sự tương tác giữa người dạy, người học và đối tượng dạy học. Tác giả đã đưa ra các yêu cầu PPDH tổ chức tương tác hành động và một nhóm phương pháp tổ chức tương tác hành động học bao gồm: Các phương pháp kịch, các PPDH bằng trò chơi, và dạy học tương tác theo lí thuyết lịch sử văn hoá về sự phát triển các chức năng tâm lí cấp cao của Vygotsky, L. S (N. T. Phan, 2005). 
Trong cuốn sách, Tương tác hoạt động Thầy - Trò trên lớp học (H. T. Dang, 2005) Tác giả đã xác định "các nguyên tắc chủ yếu của quá trình dạy học hiện đại bao gồm: nguyên tắc tuơng tác, nguyên tắc tham gia hoạt động học tập của nguời hoc, nguyên tắc tính vấn đề của dạy hoc." Từ việc phân tích các triết lý dạy học hiện đại như triết lý hợp tác, triết lý hiện sinh, triết lý thực dụng, triết lý dạy học dựa vào vấn đề, triết lý kiến tạo, ... là tiền đề rất quan trọng để xây dựng cơ sở lý thuyết cho dạy học theo QĐSPTT.

Nghiên cứu về ưng dụng công nghệ thông tin và truyền thông trong dạy họ theo quan điểm su phạm tương tác

Tác giả Meier và Nguyen (2019), Lý luận dạy học hiện đại co sở đổi mói muc tiêu, nọi dung, phuoong pháp dạy học (Meier \& Nguyen, 2019). Trong cuốn sách đã trình bày tổng quan mối quan hệ giữa các yếu tố của QTDH trong một "khung lý luận dạy hoc." Trong đó các mối tương tác giữa bộ ba người dạy, người học, đối tượng học tập được đặt trong một "tam giác dạy $h o c$ " là các tương tác cốt lõi. Các mối tương tác này được thực hiện thông qua yếu tố về mục tiêu, nội dung, phương pháp, phương tiện, hình thức, nhiệm vụ, đánh giá, tại địa điểm, thời gian xác định. Theo tác giả do tính phức hợp của QTDH nên có rất nhiều lý thuyết học tập hay các mô hình lý luận dạy học khác nhau nhằm giải thích và tối ưu hóa QTDH. Tuy nhiên mỗi lý thuyết, mô hình đều có những phạm vi ứng dụng xác định, không có mô hình lý thuyết dạy học vạn năng có thể sử dụng tối ưu cho mọi QTDH.

Trong cuốn sách, Phưong pháp và công nghệ dạy học trong môi trường su phạm tuoơng tác (Pho \& Ngo, 2011). Nhóm tác giả phân tích tổng quan về mô hình dạy học theo QĐSPTT và việc ứng dụng phương pháp và công nghệ dạy học trong môi trường này ở các loại hình nhà trường khác nhau; đưa ra cách tiếp cận mới về QĐSPTT, các PPDH tích cực đã được sử dụng trong môi trường này; khẳng định các $\mathrm{PPDH}$ tích cực chỉ được thực hiện có hiệu quả trong một môi trường giàu tính công nghệ, môi trường dạy học đa phương tiện; giới thiệu các phần mềm hữu ích được sử dụng trong dạy học. Tuy nhiên, cuốn sách chưa đề cập tới việc tổ chức dạy học theo QĐSPTT trong dạy học một môn học cụ thể.

Nghiên cứu về vận dụng quan điểm su phạm tuơng tác trong các môn học ở các nhà truoòng

Những năm gần đây, ở nước ta đã có một số công trình khoa học nghiên cứu vận dụng QĐSPTT trong dạy học ở các nhà trường mang lại kết quả nhất định, đóng góp cho sự nghiệp đổi mới giáo dục Việt Nam hiện nay:

Luận án tiến sĩ Giáo dục học, Biện pháp vận dụng quan điểm su phạm tuơng tác trong dạy học môn Giáo dục học ở các trương Đại học Su phạm (Vu, 2008), đã hướng đến đối tượng người học là sinh viên các trường Đại học Sư phạm. Đề tài luận án của các tác giả đã làm sáng tỏ bản chất lý luận của QĐSPTT, phân tích định hướng, nguyên tắc vận dụng QĐSPTT vào dạy học môn Giáo dục học.

Tiếp cận đổi mới PPDH ở cấp độ quan điểm, Tổ chức dạy học dựa vào tương tác người hoc- người học ở truoòng cao đẳng (Ta, 2010). Tác giả khẳng định: Xu thế phát triển của xã hội hiện đại đòi hỏi đội ngũ sinh viên cao đẳng không chỉ cần có kỹ năng nghề nghiệp mà còn cần các kỹ năng tương tác xã hội để phối hợp làm việc với người khác góp phần nâng cao hiệu quả công việc. Do vậy "Tổ chức dạy học dựa vào tương tác giữa người học - người học là một xu thế đổi mới PPDH nhằm thực hiện tối ưu mục tiêu đổi mới giáo dục" (Ta, 2010).

Trong luận án tiến sĩ Giáo dục học, Dạy học dụa vào tuoong tác trong đào tạo giáo viên tiểu học trình độ Đại học (T. Q. Pham, 2013), làm rõ được một số vấn đề lý luận về dạy học dựa vào tương tác; tương tác trong dạy học, bản chất của tương tác trong dạy học, đặc trưng của dạy 
học dựa vào tương tác; thiết kế được năm mô hình dạy học dựa vào tương tác.

Tiếp cận dạy học tương tác như là các phương pháp, kỹ thuật dạy học, Dạy học tương tác trong môn toán ở truòng trung học phổ thông qua chủ đề phương trình và bất phương trình (M. T. H. Do, 2015). Tác giả luận án đã khái quát lên ba hướng vận dụng lý thuyết về tương tác vào dạy học các môn học cụ thể đó là; (1) trường phái sư phạm tương tác (Interactive pedagogy) của hai tác giả Denomme và Roy (2000) (2) học tương tác theo quan niệm hiện đại (Interactive learning); (3) sự kết hợp hài hòa của hai hướng trên đó là tương tác trong lớp học (Interactive classroom).

Bài báo "Quan điểm tương tác trong dạy học toán học ở trường trung học phổ thông” (L. T. H. Nguyen \& Tran, 2012). Bài báo trình bày kết quả nghiên cứu, vận dụng QĐSPTT trong dạy học môn toán. Nhóm tác giả đề xuất 06 bước khi tiến hành dạy học tương tác gồm: (1) chuẩn bị; (2) tìm hiểu thăm dò; (3) đặt câu hỏi, lựa chọn câu hỏi để khám phá; (4) Khám phá; (5) báo cáo kết quả khám phá; (6) đánh giá. Để thiết kế được một nội dung bài học với dạy học tương tác có chất lượng thì chúng ta cần theo những nguyên tắc cơ bản sau: đúng mục tiêu bài học, tính chính xác, tính sư phạm và tính khả thi.

Bài báo "Tiếp cận sư phạm tương tác - một hướng giải pháp nâng cao chất lượng dạy học" (Y. T. H. Nguyen \& Nguyen, 2012). Nhóm tác giả bài báo đã giới thiệu các thành tố dạy học, mối tương tác giữa các thành tố đó và đưa ra mô hình dạy học trên cơ sở tiếp cận sư phạm tương tác. Đáng chú ý trong bài viết tác giả khẳng định "Su phạm tuơng tác có thể được xem xét duới nhiều khía cạnh khác nhau theo quan điểm cấu trúc hệ thống hoặc chức năng." QĐSPTT của (Denomme \& Roy, 2000) được hiểu là cách tiếp cận về hoạt động dạy học dựa trên sự ảnh hưởng tác động lẫn nhau giữa 03 tác nhân người học, người dạy và môi trường.

Tác giả bài báo "Mô hình sư phạm tương tác trong dạy học tiểu học theo định hướng phát triển năng lực" (H. T. T. Pham, 2017). Tác giả bài đề cập đến mô hình sư phạm tương tác trong dạy học tiểu học; quy trình dạy học theo QĐSPTT; nêu ra những căn cứ ứng dụng mô hình sư phạm tương tác trong dạy học theo định hướng phát triển năng lực cho học sinh tiểu học.

Những năm gần đây, trong quân đội đã có những công trình nghiên cứu có liên quan đến vấn đề về dạy học theo QĐSPTT.

Tiếp cận QĐSPTT ở góc độ PPDH, tác giả V. M. Le (2007), Hoàn thiện phương pháp dạy học các môn khoa học xã hội và nhân văn trong nhà trường quân đội (V. M. Le, 2007). Tác giả đã tiếp cận QĐSPTT ở góc độ PPDH, tác giả đã nêu lên một số đặc điểm dạy học theo QĐSPTT và nhấn mạnh “Ngoài giá trị dạy học, phuoong pháp su phạm tuoong tác còn có ý nghĩa tạo sụ phối hơp giũua nhà truòng với đơn vị trong lĩnh vưc đào tạo, góp phần thực hiện quan điểm xã hội hóa giáo dục, nguyên lý thống nhất lý luận với thực tiễn, học với hành nhà truờng với đơn vị" (p. 39). Rõ ràng, tác giả đã nhấn mạnh và đề cao vai trò của dạy học tương tác và tác động của môi trường xã hội đối với việc dạy và học.

M. D. Nguyen (2013), Đổi mói căn bản, toàn diện giáo dục và đào tạo trong các học viện, nhà truờng quân đội hiện nay (M. D. Nguyen, 2013) cho rằng: đổi mới $\mathrm{PPDH}$ là khâu quan trọng cần ưu tiên trong giáo dục và đào tạo ở nhà trường quân đội. Từ đó tác giả khẳng định: đổi mới PPDH hiện nay cần tập trung đổi mới cách dạy, cách học, chuyển từ phương pháp truyền thụ kiến thức "thầy đọc, trò ghi" sang sử dụng tổng hợp các PPDH hiện đại kết hợp với phương pháp truyền thống, phát huy tính tích cực, chủ động sáng tạo, phát triển năng lực người học. Bên cạnh đó tác giả còn cho rằng: đổi mới phương pháp học là quá trình đổi mới phương pháp tự học của người học theo hướng "lấy tụ học làm cốt." Người học với tư cách là chủ thể của hoạt động học tập tích cực thông qua các hình thức khác nhau để tích luỹ kiến thức, nâng cao khả năng nhận thức và năng lực xử lý những vấn đề từ thực tiễn theo mục tiêu yêu cầu đào tạo. 
Trong luận án tiến sĩ Giáo dục học, Vận dụng phuoong pháp so đồ hoá (Graph) trong dạy học các môn Khoa học Xã hội nhân văn ở đại học quân sụ (P. V. Nguyen, 2000) làm rõ cơ sở lý luận, thực tiễn của vận dụng phương pháp sơ đồ hoá trong dạy học, những hiệu quả của nó mang lại trong dạy học các các môn khoa học xã hội và nhân văn đại học quân sự, quy trình vận dụng, ... đề xuất của tác giả đã phản ánh đặc điểm cơ bản về dạy học tương tác. Người dạy, người học tương tác với nội dung dạy học.

Tuy không trực tiếp luận giải vấn đề vận dụng QĐSPTT trong dạy học, luận án tiến sĩ Giáo dục học, Vận dụng phuơng pháp dạy học hợp tác trong dạy hoc các môn khoa học xã hộ nhân văn ở đại học quân sư (T. V. Phan, 2010) đã đề cập nhiều khía cạnh của tổ chức dạy học theo QĐSPTT: làm rõ vai trò của người dạy, người học và mối quan hệ giữa người dạy với người học và môi trường theo kiểu dạy học hợp tác. Từ việc luận giải đặc điểm của dạy học hợp tác đã khẳng định rằng "Dạy học hợp tác là một kiểu dạy học tiên tiến, hiện đại, có nhiều nét tuơng đồng với các quan điểm tiếp cận dạy hoc hiện đại nhu: quan điểm dạy hoc "lấy học sinh làm trung tâm", "dạy học tích cưcc", "dạy học tương tác”."

Luận giải mối quan hệ người dạy, người học với môi trường dạy học thông qua tình huống dạy học, luận án tiến sĩ Giáo dục học, Xây dụng và sủ dụng tình huống trong dạy học các môn khoa học xã hội nhân văn ở đại học quân sụ (Bui, 2011) Tác giả đã luận giải mối quan hệ người dạy, người học với môi trường dạy học thông qua tình huống dạy học: Xây dựng và sử dụng tình huống dạy học có vai trò rất quan trọng trong đổi mới PPDH, làm thay đổi căn bản cách thức giảng dạy của giảng viên chuyển cách dạy thuyết trình độc thoại sang cách dạy dựa trên sự tương tác giữa người dạy, người học. Người dạy có cơ hội để thực hiện nhiều vai trò khác nhau trong dạy học, không chỉ đơn thuần là người truyền đạt kiến thức, hướng dẫn các kỹ năng, quản lý giám sát lớp học mà có vai trò quan trọng đó là định hướng, trợ giúp, hệ thống hóa kiến thức, khái quát hóa các kết luận. Mặt khác người dạy có điều kiện đi sâu tìm hiểu đặc điểm tâm sinh lý, điều kiện hoàn cảnh của người học, tạo không khí dân chủ, cởi mở, gần gũi với người học.

Như vậy, qua nghiên cứu các công trình khoa học của các giả trong quân đội cho thấy mặc dù chưa trực tiếp luận giải vấn đề dạy học theo QĐSPTT nhưng các công trình đã xem xét vấn đề này ở nhiều góc độ khác nhau, tuy nhiên điểm chung các nghiên cứu đều đi sâu luận giả về sự cần thiết phải đổi mới PPDH chuyển từ phương pháp truyền thụ kiến thức một chiều sang tăng cường sự tương tác giữa người dạy, người học với môi trường học tập, phát huy được tính tích cực, chủ động, sáng tạo, phát triển năng lực của người học để đáp ứng yêu của sự nghiệp đổi mới căn bản, toàn diện công tác giáo dục, đào tạo trong quân đội, gắn với thực tiễn hoạt động quân sự.

\subsection{Khái quát kết quả nghiên cứu của các công trình khoa học đã công bố}

Một là, việc nghiên cứu về mối quan hệ tương tác giữa người dạy và người học được nghiên cứu từ rất sớm trong lịch sử giáo dục học, còn tồn tại nhiều quan niệm khác nhau. Cấu trúc hoạt động dạy học còn khác nhau, có quan niệm của hoạt động dạy học chủ yếu quyết định bởi 03 yếu tố (Jean, 1993; Denomme \& Roy, 2000) 04 yếu tố (Thurmond \& Wambach, 2004) nhiều yếu tố (Meier \& Nguyen, 2019) tên gọi của từng yếu tố chưa có sự thống nhất. Điều này nói lên có nhiều mô hình, cách tiếp cận khác nhau về dạy học theo QĐSPTT. Việc tiếp cận QĐSPTT theo góc độ nào là phụ thuộc vào mục đích, nhiệm vụ, đối tượng, khách thể nghiên cứu, điều kiện, khả năng, môi trường vận dụng QĐSPTT;

Hai là, đa số các công trình nghiên cứu đều khẳng định rằng QTDH hiện đại về bản chất là sự tương tác giữa người dạy và người học, giữa người học với người học với môi trường dạy học. Trong đó, tương tác giữa người dạy với người học là chủ đạo. Để hoạt động dạy - học đạt 
hiệu quả cao, người dạy cần phải tổ chức tốt các hoạt động học tập theo hướng tăng cường tổ chức các hoạt động học tập tương tác;

Ba là, quan niệm về môi trường dạy học theo QĐSPTT khá đa đạng: Môi trường tương tác trực tiếp mặt giáp mặt; môi trường tương tác thực, môi trường tương tác ảo; dạy học tương tác trực tuyến thực hiện thông qua máy tính và mạng Internet. Nhất là sự tương tác giữa người học với nội dung học tập (slide bài giảng, mô phỏng, phần mềm dạy học tương tác, trò chơi, thí nghiệm thực hành ảo, ...) để lĩnh hội kiến thức là hướng được quan tâm nghiên cứu gần đây;

Bốn là, trong xu thế đổi PPDH hiện nay các nhà giáo dục học quân sự đã quan tâm, nghiên cứu vận dụng lý thuyết dạy học hiện đại vào QTDH trong nhà trường quân đội. Tuy nhiên, phần lớn các đề tài tập trung nghiên cứu mối quan hệ tương tác giữa người dạy với người học, người học với người học và mối quan hệ tương tác giữa các nhóm học tập. Mà chưa có nhiều công trình nghiên cứu một cách có hệ thống mối quan hệ tương tác giữa người dạy với người học và môi trường dạy học theo bản chất của QĐSPTT. Nói cách khác, cách tiếp cận về QĐSPTT của các công trình khoa học đã công bố của các tác giả trong quân đội thời gian gần đây cơ bản là các tiếp cận hẹp dạy học theo QĐSPTT.

\section{Kết luận}

Nghiên cứu tổng quan về dạy học theo QĐSPTT của các tác giả trong và ngoài nước nhận thấy đây là vấn đề đã được các nhà khoa học, nhà giáo dục quan tâm nghiên cứu từ rất sớm trong lịch sử. Tuy nhiên, kết quả các nghiên cứu về QĐSPTT còn mang tính lý luận chung, nên để việc vận dụng vào thực tiễn QTDH còn là một thách thức lớn, nhất là vận dụng QĐSPTT trong dạy học các môn Khoa học xã hội và nhân văn ở trường sĩ quan quân đội. QTDH ở các trường sĩ quan quân đội không những cung cấp cho người học một hệ thống kiến thức kỹ năng đã có sẵn trong sách vở mà còn phải hướng tới phát triển phẩm chất, năng lực toàn diện cho người học. Để thực hiện được yêu cầu trên phải nghiên cứu, vận dụng các quan điểm, lý thuyết, PPDH, kỹ thuật học hiện đại, có tính tương tác cao để vận dụng vào QTDH ở các trường sĩ quan quân đội.

\section{Tài liệu tham khảo}

Bui, T. H. (2011). Xây dụng và sủ dụng tình huống trong dạy học các môn khoa học xã hội và nhân văn ở đại học quân sụ [Constructing and using case studies in teaching social sciences and humanities at military university] (Doctoral dissertation). Học viện Chính trị, Hanoi, Vietnam.

Dang, H. V., \& Ha, D. T. (2009). Lý luận dạy học đại học [Theory of university teaching]. Hanoi, Vietnam: NXB Đại học Sư phạm Hà Nội.

Dang, H. T. (2005). Tưong tác thầy - trò trên lớp học [Interactive teacher-student activities in the classroom]. Hanoi, Vietnam: NXB Giáo dục.

Đảng Cộng Sản Việt Nam. (2013). Nghị quyết Hội nghị lần thứ Tám Ban Chấp hành Trung uong khóa XI [Resolution of the Eighth Conference of the Central Committee of the 11th term]. Hanoi, Vietnam: NXB Chính trị Quốc gia - Sự thật.

Do, D. N. (1997). Tiếp cận hiện đại hoạt động dạy hoc [Modern approach to teaching activities]. Hanoi, Vietnam: NXB Đại học Quốc gia Hà Nội.

Do, M. T. H. (2015). Dạy học tương tác trong môn toán ở trường trung học phổ thông qua chủ đề phuơng trìn và bát phưong trìn [Interactive teaching of high school math through the 
topic of equations and inequalities] (Doctoral dissertation). Viện Khoa học Giáo dục Việt Nam, Hanoi, Vietnam.

Ha, T. N., \& Dao, A. T. (1998). Lịch sủ giáo dục thế giới [History of world education]. Hanoi, Vietnam: NXB Giáo dục.

Jean, V. (1993). Một số vấn đề về phưong pháp giáo dục [Some problems with educational methods]. Hanoi, Vietnam: NXB Giáo dục.

Le, B. K. (1993). Tổ chức quá trình dạy học đại học [Organization of the university teaching process]. Hanoi, Vietnam: NXB Giáo dục.

Le, V. M. (2007). Hoàn thiện phưong pháp dạy học các môn khoa học xã hội và nhân văn trong nhà trường quân đội [Improving teaching methods of social sciences and humanities in military schools]. Hanoi, Vietnam: NXB Quân đội nhân dân.

Lu, T.-N., Cowie, B., \& Jones, A. (2010). Senior high school student biology learning in interactive teaching. Research in Science Education, 40, 267-289. doi:10.1007/s11165008-9107-8

Meier, B., \& Nguyen, C. V. (2019). Lý luận dạy học hiện đại [Modern teaching theory]. Hanoi, Vietnam: NXB Đại học Sư phạm Hà Nội.

Nguyen, C. V., \& Meier, B. (2012). Lý luận dạy học kỹ thuật, phuoong pháp và quá trình dạy hoc [Technical teaching theory, methods and teaching process]. Hanoi, Vietnam: NXB Đại học Sư phạm Hà Nội.

Nguyen, L. T. H., \& Tran, T. T. (2012). Quan điểm tương tác trong dạy học Toán học ở trường Trung học phổ thông [Interactive perspectives in teaching Mathematics in high schools]. Tạp chi Khoa học Đại học Su phạm Hà Nội, 4, 11-17.

Nguyen, M. D. (2013). Đổi mới căn bản, toàn diện giáo dục và đào tạo trong các học viện, nhà truờng quân đội hiện nay (Kỷ yếu hội thảo khoa học) [To radically and comprehensively renovate education and training in current military academies and schools (Proceeds of scientific conferences)]. Hanoi, Vietnam: NXB Quân đội nhân dân.

Nguyen, P. V. (2000). Vận dụng phương pháp so đồ hoá (Grap) trong dạy học các môn khoa học xã hội nhân văn ở đại học quân sụ [Applying the method of diagramming (Grap) in teaching social sciences and humanities at military university] (Doctoral dissertation). Học viện Chính trị, Hanoi, Vietnam.

Nguyen, T. C., \& Le, B. K. (2004). Phwơng pháp dạy và học đại học [Methods of teaching and learning at university]. Hanoi, Vietnam: NXB Đại học Sư phạm Hà Nội.

Nguyen, Y. T. H., \& Nguyen, L. T. N. (2012). Tiếp cận sư phạm tương tác - Một hướng giải pháp nâng cao chất lượng dạy học [Approaching interactive pedagogy - A solution to improve teaching quality]. Tạp chí Khoa học Xã hội, nhân văn và Giáo dục, 1, 130-135.

Pham, H. T. T. (2017). Mô hình sư phạm tương tác trong dạy học tiểu học theo định hướng phát triển năng lực [Interactive pedagogical model in primary school teaching with the orientation of capacity development]. Tạp chí Giáo dục, 404(2), 30-35.

Pham, T. Q. (2013). Dạy học dụa vào tương tác trong đào tạo giáo viên tiểu học trình độ đại học [Interactive-based teaching in the training of primary school teachers at the university level] (Doctoral dissertation). Viện Khoa học Giáo dục Việt Nam, Hanoi, Vietnam. 
Phan, N. T. (2005). Dạy học và phương pháp dạy học trong nhà trưòng [Teaching and teaching methods in schools]. Hanoi, Vietnam: NXB Đại học Sư phạm Hà Nội.

Phan, T. V. (2010). Vận dụng dạy học hợp tác trong dạy học các môn khoa hoc xã hội và nhân văn ơ đại hoc quân sụ [Applying cooperative teaching in teaching social sciences and humanities at military universities] (Doctoral dissertation). Học viện Chính trị, Hanoi, Vietnam.

Pho, H. D., \& Ngo, S. Q. (2011). Phương pháp và công nghệ dạy hoc trong môi truờng sư phạm tuong tác [Teaching methods and technology in an interactive pedagogical environment]. Hanoi, Vietnam: NXB Đại học Sư phạm Hà Nội.

Pometun, O. (2009). Encyclopedia of interactive learning. Ukraine: A.S.K.

Denomme, J. M., \& Roy, M. (2000). Tiến tới một phưong pháp sư phạm tuoong tác [Pour une pédagogie interactive]. Hanoi, Vietnam: NXB Thanh Niên.

Roy, M., \& Denomme, J. M. (2009). Su phạm tưong tác một tiếp cận khoa học thần kinh về học và day [Interactive pedagogy a neuroscientific approach to teaching and learning]. Hanoi, Vietnam: NXB Đại học Quốc gia Hà Nội.

Sessoms, D. (2008). Interactive instruction: Creating interactive learning environments through tomorrow's teachers. International Journal of Technology in Teaching and Learning, 4(2), 86-96.

Singh, R. R. (1991). Education for twenty-first century: Asia- Pacific perspective. Bangkok, Thailand: Unesco.

Ta, T. Q. (2010). Tổ chúc day học dụa vào tương tác người hoc - người hoc ở trường cao đẳng [Teaching organization based on learner-student interaction at colleges] (Doctoral dissertation). Đại học Sư phạm Hà Nội, Hanoi, Vietnam.

Thai, T. D. (2001). Giáo dục học hiện đại [Modern education]. Hanoi, Vietnam: NXB Đại học Quốc gia Hà Nội.

Thai, T. D. (2010). Phuoong pháp dạy học - truyền thống và đổi mói [Teaching methods tradition and innovation]. Hanoi, Vietnam: NXB Giáo dục.

Thurmond, V., \& Wambach, K. (2004). Understanding interaction in distance education: A review of literature. International Journal of Instructional Technology \& Distance Learning.

Vu, H. L. (2008). Biện pháp vận dụng quan điểm su phạm tương tác trong dạy học môn giáo dục học ơ các trường dại học su pham [The method of applying the interactive pedagogical perspective in teaching pedagogical subjects at pedagogical universities] (Doctoral dissertation). Đại học Sư phạm Hà Nội, Hanoi, Vietnam. 


\section{(c) (T) (5)}

Creative Commons Attribution-NonCommercial 4.0 International License. 